\title{
Investigation of Increased Hydraulic Conductivity of Silty Till Subjected to Freeze-Thaw Cycles
}

\begin{abstract}
REFERENCE: Makusa, Gregory P., Mattsson, Hans, and Knutsson, Sven, "Investigation of Increased Hydraulic Conductivity of Silty Till Subjected to Freeze-Thaw Cycles," Mechanical Properties of Frozen Soils, STP 1568, Hannele Zubeck and Zhaohui Yang, Eds., pp. 33-46, doi:10.1520/ STP156820120139, ASTM International, West Conshohocken, PA 2013. ${ }^{3}$
\end{abstract}

\begin{abstract}
The hydraulic conductivity of silty till increases when the till is subjected to freeze-thaw cycles. A dramatic increase normally occurs after the first freeze-thaw cycle, and the magnitude generally depends on the initial or molding water content. Freezing of silty till causes aggregations of clods and the formation of macrostructure. The initial or molding water content determines the number of freeze-thaw cycles required to complete the agglomeration of clods and the formation of stable macrostructures, which in turn controls the hydraulic conductivity of compacted specimens frozen and thawed in the laboratory. The findings of this study show that for specimens compacted wet of the optimum water content, a significant increase in the hydraulic conductivity was measured after the first freeze-thaw cycle. When specimens were compacted at the optimum water content, a number of freeze-thaw cycles were required in order to obtain the corresponding significant increase in the hydraulic conductivity.
\end{abstract}

KEYWORDS: hydraulic conductivity, freeze-thaw, silty till, microstructure, macrostructure, dry cover, clods

\footnotetext{
Manuscript received November 2, 2012; accepted for publication May 29, 2013; published online August 22, 2013.

${ }^{1}$ Dept. of Civil, Environmental and Natural Resources Engineering, Luleå Univ. of Technology, SE 97187, Luleå, Sweden (Corresponding author), e-mail: gregory.makusa@ltu.se

${ }^{2}$ Dept. of Civil, Environmental and Natural Resources Engineering, Luleå Univ. of Technology, SE 97187, Luleå, Sweden.

${ }^{3}$ ASTM Symposium on Mechanical Properties of Frozen Soils on January 31, 2013 in Jacksonville, FL.
}

Copyright $(0) 2013$ by ASTM International, 100 Barr Harbor Drive, PO Box C700, West Conshohocken, PA 19428-2959. 